\title{
Importance of Etch Film Formation During AC Controlled Pitting of Aluminium
}

\author{
Maria Tzedaki ${ }^{1}$, Iris De Graeve1, Bernhard Kernig², \\ Jochen Hasenclever ${ }^{2}$ and Herman Terryn ${ }^{1}$ \\ ${ }^{1}$ Vrije Universiteit Brussel, \\ ${ }^{2} \mathrm{HYDRO}$ Aluminium Bonn \\ ${ }^{1}$ Belgium \\ ${ }^{2}$ Germany
}

\section{Introduction}

Over the last decades much research has been dedicated and reported in literature on the Alternating Current electrograining (A.C. electrograining) mechanism and the parameters that change the final pitting morphology of electrograined aluminium. The reason is the increasing industrial demand every year (currently estimated to be $800,000,000 \mathrm{~m}^{2} /$ year) for high quality litho-printing and super capacitors for energy storage. Both applications relay on the production of a controlled roughened surface on aluminium foil which can be achieved through A.C. electrograining. In this case pitting is used as a surface treatment for the production of a larger surface area with uniform pits.

In the past, research focused on different conditions of the A.C. electrograining of aluminium in relation to the final pitting morphology. The charge density, the wave shape of the applied current, the electrolyte concentration, the frequency or the temperature are factors that were studied extensively. The industrial application of the A.C. electrograining process makes it very important to understand and correlate all the parameters which affect the graining. The mechanism which initiates or affects the final morphology needs to be understood. In this chapter we will present an overview on the influence of the different A.C. electrograining conditions on the final pitting morphology, with the focus mainly on the smut film formation. The latter has proven to play an important role during the A.C. electrograining but little correlation was shown so far between the smut film formation and the pitting morphology. We will present in this article the importance of the smut film formation mechanism during the A.C. electrograining of aluminium and the $\mathrm{H}_{2}$ evolution, taking place during the cathodic half cycle. Conditions, such as the applied potential, the electrolyte concentration, the frequency and the charge density are important to be presented since they play a crucial role in the creation of the final pitting morphology of aluminium.

Much effort has recently been put towards understanding the $\mathrm{H}_{2}$ evolution; therefore it is important to include in this chapter reported differences observed in gas retention within the etch smut film for different electrochemical conditions and relate these differences to the final smut morphology. 
The aim of this article is to gather information available on the etch smut morphology and the smut formation mechanism for a better understanding of the influence of the etch film on the final pitting morphology.

\section{A.C. electrograining mechanism}

A.C. electrolytic graining or electrograining is a process used for the creation of a uniformly pitted morphology on aluminium surfaces. Electrograining can increase the specific area of a smooth aluminium foil by up to a factor of 200 [Ono \& Habazaki, 2011, Dyer \& Alwitt 1981]. The process is industrially applied in lithographic printing plates, where a larger surface area is necessary in order to enhance the water retentive properties of the aluminium and to improve the adhesion of the photosensitive coating which is deposited after electrograining and anodising of the aluminium substrate. Also in the preparation of aluminium capacitor foils an electrochemical etching of aluminium is required. This enlarges the surface area of the electrolytic capacitor electrodes permitting a reduction both in cost and in size of the capacitor [Jackson, 1975].

The aluminium substrate is electrograined in an electrolytic cell using a suitable electrolyte, usually a strong acid like hydrochloric acid $(\mathrm{HCl})$ or nitric acid $\left(\mathrm{HNO}_{3}\right)$. Additives such as citric acid, nitric acid, boric acid etc. are used to improve the uniformity of the pits [Terryn, 1987]. The required morphology is created by applying a sinusoidal alternating current (Figure 1) or voltage which determines the initiation, propagation and repassivation of key pits during each period of the AC cycle, mostly with a frequency of 50 or $60 \mathrm{~Hz}$.

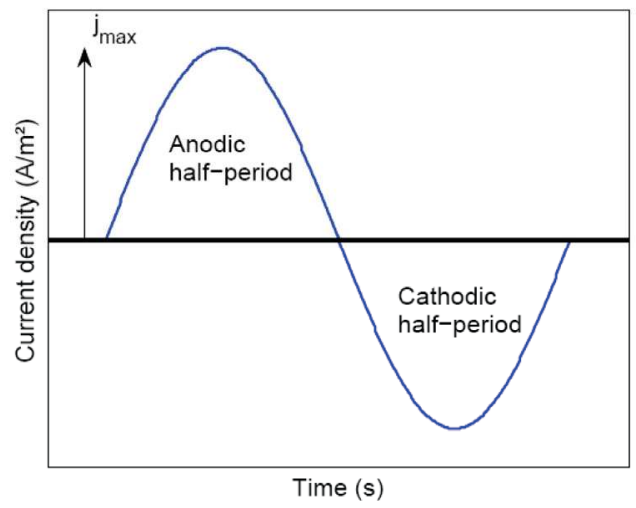

Fig. 1. Applied alternative AC current waveform during one period

During the anodic half cycle oxidation of aluminium to $\mathrm{Al}^{+3}$ ions occurs; dissolved aluminium is removed to the bulk of the solution and cubic pits are formed [Dyer \& Alwitt, 1981]. The reactions taking place during the positive polarisation are:

$$
\begin{gathered}
\mathrm{Al} \rightarrow \mathrm{Al}^{3+}+3 \mathrm{e}^{-} \\
2 \mathrm{H}_{2} \mathrm{O} \rightarrow \mathrm{O}_{2}+4 \mathrm{H}^{+}+4 \mathrm{e}^{-}
\end{gathered}
$$


In the cathodic half period, due to hydrogen gas evolution (reaction 3), the $\mathrm{pH}$ can rise above 5 . The previously formed $\mathrm{Al}^{3+}$ ions which were not yet removed from the surface, precipitate as aluminium hydroxide $\mathrm{Al}(\mathrm{OH})_{3}$ (reaction 4). Aluminium hydroxide is insoluble in water and precipitates as a white gel [Vargel et al, (2004), Dyer \& Alwitt, 1981]. The latter together with aluminium particles, water and ions from the electrolyte create an amorphous etch film, called smut layer, formed in a colloidal phase which masks the pits and causes an increase in the potential. [Terryn, 1987, 1988, 1991a, 1991b, Laevers, 1992, 1995]

$$
\begin{gathered}
2 \mathrm{H}^{+}+2 \mathrm{e}^{-} \rightarrow \mathrm{H}_{2} \\
\mathrm{Al}^{3+}+3 \mathrm{OH}^{-} \rightarrow \mathrm{Al}(\mathrm{OH})_{3}
\end{gathered}
$$

A further increase of the $\mathrm{pH}$ above 9 will result in oxidation of aluminium to $\mathrm{AlO}_{2}$ ions (reaction 5); these will eventually precipitate as aluminium hydroxide when the $\mathrm{pH}$ of the layer close to the surface decreases rapidly [Pourbaix, 1974, Terryn, 1987, Laevers, 1995, Buytaert, 2006, Wilson et al, 2008, Hülser, 1955]. The decrease of the $\mathrm{pH}$ can be due to protons $\left(\mathrm{H}^{+}\right)$coming from the bulk electrolyte and/or oxygen evolution during the abovementioned reactions. [Laevers, 1995, Buytaert, 2006, Pourbaix, 1974, Terryn, 1987,]

$$
\begin{gathered}
\mathrm{Al}+4 \mathrm{OH}^{-} \rightarrow \mathrm{AlO}_{2}^{-}+2 \mathrm{H}_{2} \mathrm{O}+3 \mathrm{e}^{-} \\
\mathrm{AlO}_{2}^{-}+2 \mathrm{H}_{2} \mathrm{O} \rightarrow \mathrm{Al}(\mathrm{OH})^{-} 4 \\
\mathrm{Al}(\mathrm{OH})^{-} \rightarrow \mathrm{Al}(\mathrm{OH})_{3}+\mathrm{OH}^{-} \\
4 \mathrm{OH}^{-} \rightarrow \mathrm{O}_{2}+2 \mathrm{H}_{2} \mathrm{O}+4 \mathrm{e}^{-}
\end{gathered}
$$

The cathodic half period involves the re-passivation of the substrate resulting in a redistribution of attack during the subsequent anodic half-period, which is necessary for the creation of a uniform pitting morphology [Dowell, 1979, Terryn, 1987, Buytaert, 2006]. A schematic representation of the electrograining process can be seen in Figure 2.

Depending on the electrolyte, the pit initiation and propagation can differ and the pitting morphology can vary between a uniform, non-uniform and etch-like morphology. The formation of pits can also vary between crystallographic, shallow and worm-like pits as illustrated in Figure 3.

The resulting pit shape depends on whether the process is activation or diffusion controlled. During the activation controlled process, metal atoms are removed from various crystal planes resulting in the formation of crystallographic pits [Smialowska, 1986]. This condition occurs during the first stages of pit growth where only small changes in $\mathrm{Cl}^{-}$concentration occur within the pit [Smialowska, 1986]. When chloride ions undergo chemisorptions on the crystallographic facets on the bottom of the pits the potential increases and solution concentrates within the pits. Here diffusion is the predominant phenomenon resulting in the formation of hemispherical pits [Smialowska, 1986].

The properties of the passive film influence the initiation of the pit but they do not contribute significantly in the pit growth. For stable pit growth a high concentration of $\mathrm{Cl}^{-}$ and a low $\mathrm{pH}$ inside the pit eliminate the repassivation at the initial stage. After longer times the pit growth is a diffusion controlled process [Smialowska, 1999]. 


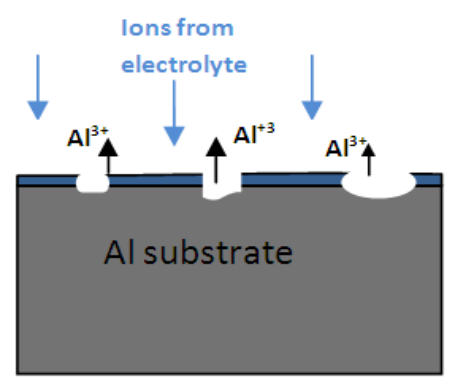

$1^{\text {st }}$ Anodic half period

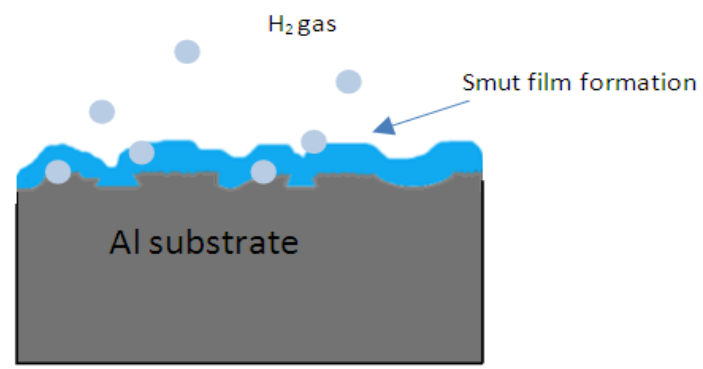

$1^{\text {st }}$ Cathodic half period

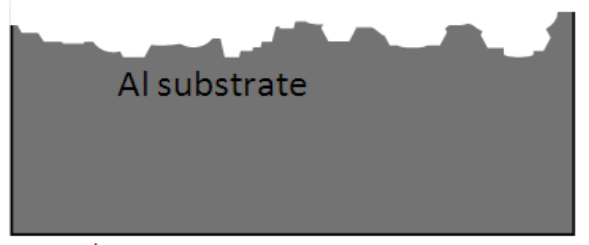

$2^{\text {nd }}$ Anodic half period

Fig. 2. A.C. electrograining mechanism of aluminium
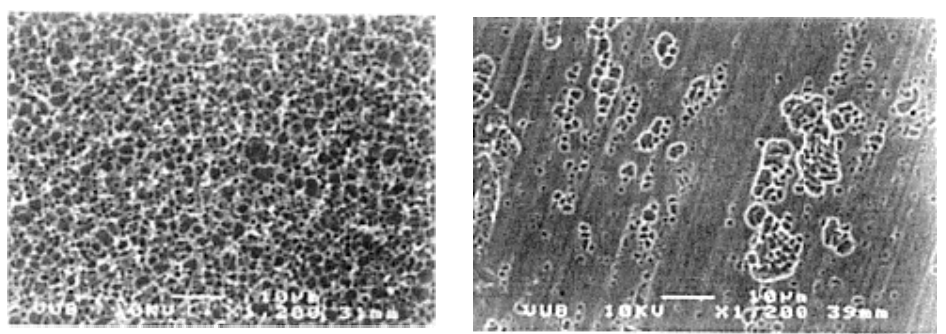

Fig. 3. Shallow (left) and worm-like (right) pitting of $\mathrm{Al} 99.99$ in $\mathrm{HNO}_{3}, 50 \mathrm{~Hz}$ [Laevers, 1995]

Koroleva showed that by controlling the extent of anodic or cathodic polarisation and by considering the local interfacial solution conditions, tailored and optimised pitting morphologies are obtained. This can be understood by examining the cathodic polarisation which promotes the pit initiation and eliminate pit growth; a high population of fine hemispherical pits is observed after electrograining with cathodic bias [Koroleva, 2005].

How the electrograining conditions can influence the uniformity of the pits and the final surface morphology will be discussed in the following paragraphs.

\subsection{Influence of the electrolyte on the electrograining process}

For a uniform pitting morphology on an aluminium substrate, a suitable electrolyte must be chosen. A strong inorganic acid such as hydrochloric or nitric acid has been mainly used 
and studied extensively the past years. Each one can give a uniform pitting morphology at a suitable temperature and concentration and with the appropriate applied current density. The solutions used for graining are diluted and there should be a balance between the aggressiveness of the electrolyte, necessary to initiate the pitting, and the low anion concentration, necessary for the re-passivation to occur [Dowell, 1986]. $\mathrm{HCl}$ is suitable at a range of 0.5 to $10 \% \mathrm{v} / \mathrm{v}$ whereas less aggressive acids need a higher concentration [Dowell, 1986].

$\mathrm{HCl}$ gives a characteristic crystallographic pitting morphology whereas $\mathrm{HNO}_{3}$ results in a shallower pitting structure [Laevers et al, 1993, Terryn 1987, Bridel et al, 1983]. The density and the number of pits are proportional to the electrolyte aggressiveness and the substrate conditions, whereas the pit size is related to the local anodic charge passed [Laevers et al, 1993, Terryn, 1988, Dyer \& Alwitt, 1981, Dowell, 1979, 1986]. The use of Hydrofluoric Acid leads to the formation of surfaces that are made of significantly smaller, shallower and more uniform pits with a much higher pit density as it is illustrated in Figure 4 [Wilson, 2006]. The presence of hydrofluoric acid in solution leads to both a rapid dissolution of the second phase particles and a breakdown of the protective oxide film with pit initiation as a result of the presence of highly aggressive F- ions in the solution [Wilson, 2006].
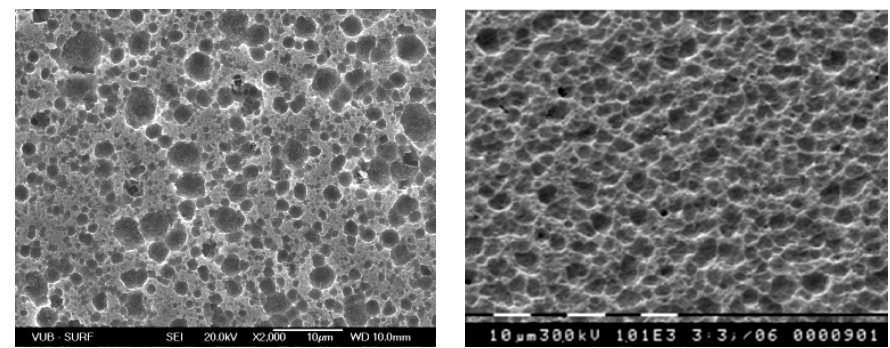

Fig. 4. Pitting morphology of AA 1050 after A.C. electrograining in $12.5 \mathrm{~g} \mathrm{HCl}$ (left) without $\mathrm{HF}$ and with addition of $1.25 \mathrm{~g} / 1$ Hydrofluoric Acid (right)

Several additives are also important especially in industrial processes, such as acids and aluminium salts e.g. aluminium chloride or aluminium nitrate.

The use of additives such as citric acid, disodium phenyl phospate dihydrate (DPPD), acetic acid etc. can improve the uniformity of the pits [Terryn, 1987]. Acetic acid can catalyse the hydrogen evolution reaction. Acetate ions are involved in inhibiting the reactions at the surface either by surface deposition or as a competitor ion to chloride. The use of the DPPD as an additive decreases the dissolution reaction of aluminium, and polarisation data has shown a shift in the pitting potential to higher values. The increased surface inhibition by the addition of DPPD is caused by the formation of a protective layer on the aluminium.

An interesting study on the influence of the additives during the electrograining was done by Wilson et al, (2008) who evaluated through NMR studies the differences induced by additives in a hydrochloric acid electrograining solution regarding the smut and the pitting morphology. The addition of DPPD or citric acid was proven to deteriorate or enhance respectively the pit uniformity. Further, the addition of citric acid causes the formation of a more porous smut layer and a final surface morphology with larger pits and fewer plateau areas in comparison with the morphology produced in $\mathrm{HCl}$ electrolyte. 
The addition of $\mathrm{H}_{2} \mathrm{SO}_{4}$ decreases the pit cluster size and increases pit-on-pit growth. Sulfate ions that are absorbed on the surface can impede the nucleation and the pit-on-pit propagation [Ono \& Habazaki 2009]. A suitable sulfate concentration in the etchant can lead to a deep and homogenously etched layer with high surface area [Ono \& Habazaki 2009]. It was shown previously that sulfate ions could shift the pitting potential in the positive direction [Tomcsanyi et al 1989, Kim et al 1999, Lee et al 2000, Ono \& Habazaki 2009]. This was later interpreted as the elimination of the competitive adsorption of sulfate ions by chloride ions [Ono \& Habazaki 2009]. The rise of the pitting potential indicates the impediment of pit initiation of pure aluminium by sulfate ions [Kim et al, 1999, Ono \& Habazaki 2009]. It was also observed that an excess of $\mathrm{H}_{2} \mathrm{SO}_{4}$ in the electrolyte promotes the formation of an etched layer with uniform thickness, since the pit formation is suppressed on the aluminium surface [Ono \& Habazaki 2009].

Lin and $\mathrm{Li},(2006)$ on the other hand had a different observation regarding the pitting formation in the presence of sulfate ions. They observed that the formation of strings of cubic pits was suppressed by the sulfate ions and the pit formation of the aluminium surface was enhanced.

\subsection{Potential evolution during the electrograining process}

Dimogerontakis, (2007) and Laevers, (1995) studied the changes in anodic and cathodic potentials during the electrograining, proposing a mechanism for the electrograining in $\mathrm{HCl}$. It was observed by Dimogerontakis that within the first second of the electrograining three subregions are observed (Figure 5). Within the first few ms both the anodic and cathodic potential increases strongly due to the dissolution of the second phase particles that are distributed at the surface and the possible build up of dissolution products. In the second region the anodic potential decreases to a minimum value, which is correlated to the degradation of the initial protective oxide film present on the surface and to the initiation of the crystallographic pitting of the aluminium surface. A third region is observed where both anodic and cathodic potential increases mainly due to the deposition of etch product during the negative half period, which begins at the end of the second region. Moreover the cathodic reaction has a greater hindrance from the smut than the aluminium dissolution.

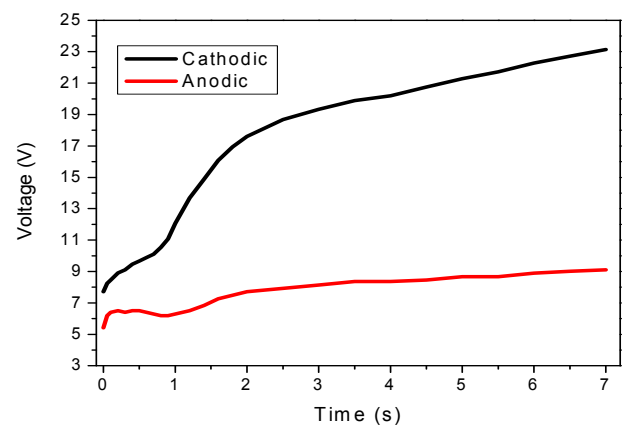

Fig. 5. Anodic and Cathodic peaks of the potential vs. time during the A.C. electrograining in $\mathrm{HCl}$ 
The amount of charge passing through the surface during the anodic half cycle is given by the following equation [Laevers et al, 1992, 1993]

$$
\frac{\text { Qperiod }}{2}=\int_{0}^{\pi} J_{\max } \cdot \sin \omega t \cdot d t=-\frac{J_{\max }}{\omega}[\cos \omega t]_{0}^{\pi}
$$

and the local anodic charge [Laevers et al, 1992, 1993] is

$$
q_{p i t}=\frac{\frac{q_{\text {period }}}{2}}{\text { PitNumber }}
$$

where $J_{\max }\left(\mathrm{A} / \mathrm{m}^{2}\right)$ is the maximum current density and $\omega=2 \pi \mathrm{f}$, with $\mathrm{f}(\mathrm{Hz})$ the electrograining frequency.

From the previous two equations it can be concluded that by decreasing the frequency of the graining the period of time during which the anodic polarisation takes place increases, while an increase in the current density promotes the oxidation of aluminium [Laevers et al, 1993].

Laevers et al, $(1992,1993,1998)$ mention that the response potential (cell voltage including the ohmic drop over the electrolyte) during the electrograining increases as a function of increasing current density, but show that in $\mathrm{HCl}$ the response potential is independent of the current density imposed. This leads to the conclusion that in $\mathrm{HCl}$ the electrograining of aluminium was controlled by aluminium oxidation and hydrogen gas evolution, which is a mass transport phenomenon, and thus by the transport conditions of reactants and products at the electrode surface. The presence of the smut layer has an influence on the mass transport phenomena affecting the electrical properties of the electrode/solution interface.

Lee et al (2000) showed that the exposed metal surface at the bottom of the micro-pits that are formed during the cathodic polarization acts as a preferential site for $\mathrm{Cl}^{-}$ions attack during the following anodic half cycle. Thus with a sufficient cathodic polarization the formation of micro pits can take place, promoting the corrosion of pure aluminium [Lee et al 2000].

Ono and Habazaki, (2010) proved that there is no influence of the current waveform (direct, anodic or square) on the amount of dissolved aluminium, but it changes the etch morphology from angular pits (direct current) to large hollow pits at low density (anodic current) and uniform etch films (for a square wave).

\subsection{Influence of the substrate on the electrograining process}

Most of the commercial aluminium alloys have a relatively high concentration of magnesium, iron, silicon and manganese, therefore it is important to show the influence that those elements have on the electrochemical properties of aluminium.

It was observed that local, coarse pit development is due to the presence of intermetallic particles [Terryn, 1987]. The intermetallics can act as cathodic sites and therefore anodic dissolution can take place at the interface of the intermetallic with the aluminium matrix [Terryn, 1987, 1988]. In this way the locally concentrated current reduces the amount of the 
effective current available for electrograining and thus for pit initiation or propagation [Terryn, 1987, 1988].

Dowell, (1986) mentioned that intermetallic particles (such as $\mathrm{FeAl}_{3}, \alpha \mathrm{Al}-\mathrm{Fe}-\mathrm{Si}$ and in less activity $\beta \mathrm{Al}-\mathrm{Fe}-\mathrm{Si}$ ) act as sites for pit initiation. He also showed that grain boundaries act as preferential sites for the pit development whereas alloy elements such as copper, iron and zinc give more plateau areas in the final pitting morphology. $\mathrm{Mg}, \mathrm{Si}$ and $\mathrm{Mn}$ did not appear to have a significant influence on the pitting morphology. Even though many pits are initiated at the sites of intermetallic particles there were many particles (around 50\%) that were observed as inactive in the pit generation. The mechanism proposed for the initiation at intermetallic particles was that intermetallics do not form a protective oxide layer, therefore even if they are electrochemically less negative than the aluminium they dissolve faster revealing the underlying aluminium surface, which can then act as initiation point.

Laevers, (1996) presented the influence of manganese on the electrograining of aluminum. A more uniform final pitting morphology was observed when the amount of manganese present in solid solution was decreased, but this could only be noticed in the more advanced stages of the graining process.

On the influence of iron and silicon Laevers, (1995) showed that when iron is present in solid solution, the average pit is shallower, whereas when silicon is present a non uniform morphology is observed with merged hemispherical pits, worm like pits and unattacked surface.

$\mathrm{Zn}$ and $\mathrm{Mg}$ promote a quick initiation of pits due to the more effective current distribution, which leads to a convoluted surface with larger grains and eliminated plateau areas [Sanchez et al, 2010].

Little information is available regarding the grain boundaries and the grain orientation in relation to specific preferential sites for the pitting initiation. It was observed that there were only $30 \%$ more pits at boundaries than expected from a random distribution [Dowell, 1986]. Cubic pits on the other hand are characteristic of the attack on (100) crystallographic planes because impurities segregate to cellular boundaries in [100] direction [Martinez-Caicedo et al 2002, Koroleva et al, 2005]. The segregates enhance cathodic activity, increasing the response potential [Martinez-Caicedo et al, 2002]. It was also observed that the subgrain boundaries could be the pit nucleation sites at the onset of electrograining [Marshall et al, 1995].

Two effects of microcrystallization on the pitting behaviour of pure aluminium are reported: (1) the rate of pit initiation is accelerated; (2) the pit growth process is impeded. This leads to the enhancement of pitting resistance for microcrystallized aluminium [Meng et al, 2009]

During the industrial rolling of aluminium sheet, rolled-in oxides are formed, creating a disturbed subsurface layer [Buytaert, 2006]. This alters the surface morphology of the aluminium substrate and thus influences the electrograining in $\mathrm{HCl}$ or $\mathrm{HNO}_{3}$ solutions. It was observed that a large amount of ungrained rolled-in oxides remains even after graining at high charge densities [Rodriguez, 2011]. The interface between rolled-in oxides and aluminium matrix can act as a weak point for the pit initiation, therefore an etching was proposed as a necessary pre-graining step [Rodriguez, 2011]. 


\section{Smut film formation and morphology}

It is known that during electrograining an etch film is formed masking the aluminium surface, mainly composed of hydrated aluminium (Figure 6) [Thompson \& Wood, 1978, Dowell 1986, Terryn, 1987, Marshall, 1995 Laevers, 1996, Amor \& Ball, 1998]. The film formation mechanism, morphology and weight differ upon different graining conditions therefore a thorough investigation of several parameters is necessary.
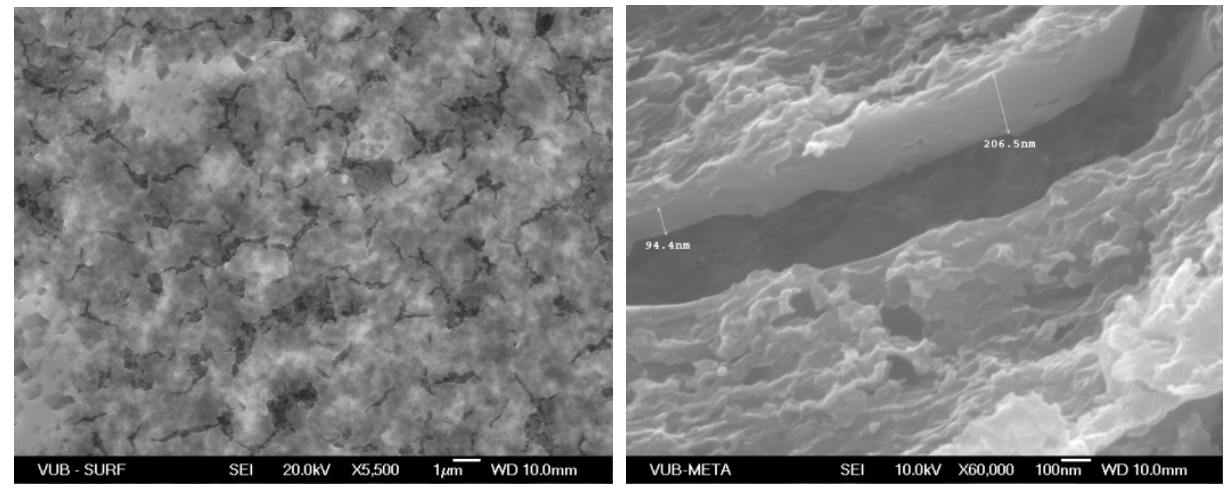

Fig. 6. Smut film morphology of aluminium sheet electrograined in $\mathrm{HCl}$ at $50 \mathrm{~Hz}$ top view(left) and bended \& cracked sample(right) [Raes, 2009]

Dowell, (1979) showed that the cell voltage undergoes a proportional increase to the weight of smut film formed during graining in $\mathrm{HCl}$. This indicates that the smut film causes an increase in the resistance to current flow.

As it was observed by Dyer and Alwitt, (1981) cubes propagate from new different point gaps inside each cube due to the weak points in the protective etch film. Whereas during direct curent etching of alumium under the same conditions no smut is formed, and cubes are formed by subsequent propagation outward of the first cube. The presence of the smut changes the pit formation mechanism and prevents the outward propagation. This indicates that the smut layer plays an important role in the final pitting morphology. The thickness and the morphology of the smut are yet to be examined in order to fully identify their role.

Laevers, (1995) observed that by imposing the same conditions during electrograining in $\mathrm{HCl}$ and in $\mathrm{HNO}_{3}$ electrolytes, the amount of etch product is the same but the morphology differs. The smut formed in $\mathrm{HCl}$ is a non uniform mud-like layer whereas in $\mathrm{HNO}_{3}$ smut is formed at the rim of the regular hemispherical pits [Laevers, 1993]. He also mentioned that if the amount of $\mathrm{Al}^{3+}$ ions, precipitated as aluminium hydroxyde is low, hemispherical pits with walls decorated with a high population density of cubic shaped key pits will be formed. If a high amount of hydroxyde is precipitated, an etch like morphology will be obtained. This indicates that the development of the surface morphology is influenced by the mechanism of development of the etch layer.

In the presence of HF a thin and highly porous etch film with numerous superfine pits on the surface is observed [Wilson, 2006]. Only a very thin, non-uniform layer of smut can be deposited in the presence of $\mathrm{HF}$ as a result of both the highly aggressive nature of the $\mathrm{F}$ - ions 
present and the production of highly soluble corrosion products compared to those produced in $\mathrm{HCl}$ [Wilson, 2006]. The activation of the surface by the fluoride ions and the lack of formation of a compact etch film allows the whole of the aluminium surface to be available to undergo graining reactions [Wilson, 2006]. Unlike the case of the hydrochloric acid where a build up of smut can lead to some blocking of the surface, especially in the regions proximal to the early pits that are formed [Wilson, 2006]. This means that as the electrograining process progresses the area susceptible to graining is reduced leading to continued reaction at pre-existing pits, which in turn leads to the observation of larger and deeper pit morphologies [Wilson, 2006].

The etch film itself is amorphous [Lin et al, 2001, Laevers, 1995] but tends to crystallize when irradiated by $200 \mathrm{keV}$ electrons. Smut is formed during the cathodic half cycle of the electrograining by a dissolution/precipitation mechanism caused by the production of $\mathrm{H}_{2}$ resulting in high local $\mathrm{pH}$ values [Thompson, 1978].

In recent studies it was observed that the addition of additives on the electrolyte can influence the smut morphology. The addition of acetic acid is shifting the $\mathrm{pH}$ in lower values thus producing a smut with very small pores [Wilson, 2008]. The porous smut layer increases the amount of aluminium dissolution or pit initiation resulting in a final surface morphology with less plateau areas [Wilson, 2008]. On the other hand it was shown that the addition of DPPD shifts the interfacial $\mathrm{pH}$ to higher values, reducing the dissolution rate of aluminium; therefore a pitting morphology with few but large pits surrounded by large plateau areas is observed [Wilson, 2008].

Dimogerontakis et al, (2006) noticed that by increasing the current density the amount of produced smut increases as a result of the high concentration of aluminium inside the pits during the anodic half period and of the local increase of the $\mathrm{pH}$ during the cathodic half cycle. This resulted in a decrease of the population density of the pits and to an enhanced pit growth. Thus at high current we can obtain less but bigger pits.

Lin and Chiu, (2005) showed that the variation of the duration time of the anodic, $t_{a}$ to cathodic, $t_{c}$ half cycle changes the thickness of the smut. Smut is decreased by increasing the $t_{a} / t_{c}$ ratio while the average size of the individual hemispherical pits increases. This indicates that during the anodic half cycle the pits grow through the dissolution of aluminium while the etch film is formed during the cathodic half cycle when local $\mathrm{pH}$ increases due to hydrogen gas evolution. Moreoever they noticed that the etch film in some areas was pushed away from the surface by certain forces exerced on the interface. It is believed that the pressure accumulated within the hydrogen bubbles or produced when $\mathrm{H}_{2}$ gas leaves the smut surface gives space for new pit initiation in the aluminium substrate during the anodic half cycle. When the etch film reaches a certain thickness, the conduction resistance increases, the further pit growth will be prevented and consequently new pits will be initiated elsewhere.

\subsection{Hydrogen gas evolution}

The presence of hydrogen gas through reaction 2.3 can cause the increase of the local $\mathrm{pH}$, which eventually causes the precipitation of aluminium hydroxide and the formation of the smut layer, masking the pitting morphology. In this paragraph we will try to understand the mechanism of the hydrogen gas evolution while it is released and leaves the smut and 
identify whether there is a relation between the $\mathrm{H}_{2}$ evolution, the morphology of the smut and the pitting morphology.

The reduction of $\mathrm{H}^{+}$during the cathodic half period was observed to be a mass transport controlled phenomenon [Laevers, 1995]. This indicates that the amount of precipitated aluminium hydroxide will be influenced by the time needed for sufficient $\mathrm{H}^{+}$to be gathered at the surface for the $\mathrm{pH}$ to rise above 5. The amount of the precipitated aluminium hydroxide is determined by the surface area, which is taking part in the active dissolution of aluminium [Laevers, 1995].

Hydrogen gas evolution during the cathodic half period may cause the transition of the pit initiation from flaws of the film to sites by removal or cracking up of the protective oxide film. By increasing the treatment time or the charge density, the growth rate is not the same for all pits.

Few recent publications can be found regarding the hydrogen gas evolution during the cathodic half cycle of the electrograining of aluminium.

Tomasoni et al, (2010) showed that by using a rotating aluminium disk as working electrode, the hydrogen bubble size and the potential during the electrograining in $\mathrm{HCl}$ are increasing at the same rate and show the same transient in time. As the pit diameter increases, the bubble departure time from the electrode decreases whereas during region III (as indicated by Dimogerontakis and Terryn, (2007)) it was noticed that the smut layer is filled, at decreasing rate, by gas while growing: the hydrogen flux from the electrode to the bulk solution is thus increasing in time and the bubble break-off diameter increases as well.

Small Angle X-ray Scattering (SAXS) is proposed to be able to characterize $\mathrm{Al}(\mathrm{OH})_{3}$ gels [Bale \& Schmidt, 1959, Christensen et al, 1982, Sinko et al, 1999]. The aluminium hydroxide particles inside precipitated gels have been considered as oblate spheroids (platelets) or polydisperse spheres that are made from individual (solid) aggregated $\mathrm{Al}(\mathrm{OH})_{3}$ molecules [Bale \& Schmidt, 1959, Bottero, 1980, 1982, Christensen et al, 1982, Bradley, 1993, Sinko et al, 1999]. Those aggregate particles can agglomerate inside the gel as seen from SAXS measurements [Bale \& Schmidt, 1959, Sinko et al, 1999].

It is known that smut is an amorphous $\mathrm{Al}(\mathrm{OH})_{3}$ gel, with a dry thickness less than $1 \mu \mathrm{m}$ [Thomspon \& Wood, 1978, Terryn et al, 1991a, 1991b, Lin et al, 2001]. In recent studies using small angle $x$-ray scattering it was shown that hydrogen is retained in the smut, playing an important role in the process [Hammons et al, 2010]: scattering data can be presented as a $\log$ to $\log$ plot of the intensity, $I$, versus the scattering vector, $q$, which is related to the angle of each intensity measurement. The size, shape and structure of particles can be determined from SAXS data. During the electrograining there is significant solution bubbling which increases the transmission compared to subsequent frames where there is lower transmission due to lower amount of gas bubbles in the beam path. The first SAXS data showed that there is a significant volume fraction of gas within the gelatinous smut layer in $\mathrm{HCl}$ [Hammons et al, 2010]. When DPPD was used as an additive in the electrolyte, less hydrogen fraction was detected in the smut so it was concluded that hydrogen can permeate through the smut in a more uniform manner without damaging it to a significant extend and therefore the dissolution occurs in a more homogeneous way [Hammons et al, 2010]. 
The reason why gas is retained in the smut is yet to be elucidated but it is assumed to be related to the gas release during or after the electrograining [Hammons, 2011]. Gas release after electrograining and gas diffusion can be estimated through SAXS measurements, but gas permeation during the electrograining is difficult to study [Hammons, 2011].

Gas release after electrograining is characterized by some parameters correlated to the gas diffusivity of the smut and to the total gas release [Hammons, 2011]. These parameters are considered to be functions of how well the smut can accommodate gas release in the absence of a pressure drop [Hammons, 2011].

A mechanism for the gas release was proposed by Hammons, (2011) through data collected from scattering images using in situ Small Angle X-ray Scattering (SAXS). It has been suggested that pores or water passageways that can facilitate gas permeation during electrograining close after the electrograining, and as such the gas is trapped inside the smut under certain conditions [Hammons, 2011] as illustrated in Figure 7. However, at a higher frequency and with the incorporation of additives, pores do not collapse and form a tortuous porous network that causes an increase in the pressure of the hydrogen gas near the interface [Hammons, 2011].

By observing the pitting morphologies after desmutting of the samples it was seen that the interfacial gas pressure can influence the final pitting morphology and give a more etch like morphology, as was observed beneath smut with little porosity, whereas at higher smut porosity a more uniform morphology is observed [Hammons, 2011].

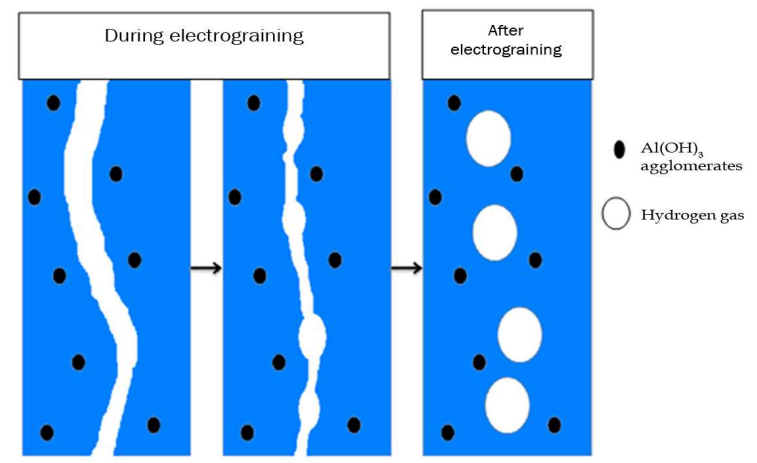

Fig. 7. Mechanism for smut permeation during electrograining where a passageway opens around the $\mathrm{Al}(\mathrm{OH})_{3}$ agglomerates and after electrograining the pores collapse leaving behind retained gas (white) [Hammons, 2011]

The use of additives and the gas release behavior was also examined with SAXS. Smut formed with citric acid has similar gas diffusion properties of that with $\mathrm{HCl}$ [Hammons 2011]. Based on the presence of large pores, high gas diffusion and low gas retention, smut was formed with DPPD [Hammons 2011]. These large pores are correlated with a surface morphology that contained very deep pits [Hammons 2011]. This work is yet to be published.

A difference in the smut porosity was observed with different additives as reported previously. The additives increase the smut porosity, compared to the reference sample that 
was grained only in $\mathrm{HCl}$. The addition of citric acid resulted in a smooth smut morphology, similar to $\mathrm{HCl}$, but with more porosity. Although a gas release mechanism similar to that of a $\mathrm{HCl}$ electrograined sample was experimentally observed in the SAXS data, an increase in the measured potential indicated that some open pore permeation was possible and could explain the difference in the final pit morphology, compared to the reference $\mathrm{HCl}$ electrograined sample [Hammons, 2010, 2011].

Electrochemical impedance spectroscopy was also used to describe the pitting formation mechanism. Brett, (1990) proposed a multistep dissolution mechanism by considering that surface aluminium atoms are oxidised stepwise until a soluble aluminate film is formed. It was concluded that migration takes place and therefore in a transient solution the soluble products are removed easily while increased mass transport supplies larger quantities to the electrode surface [Brett, 1990]. In an upcoming publication we will show that the Multisine Electrochemical Impedance Spectroscopy can give more valuable information regarding the presence of hydrogen trapped inside the smut. In addition to the known effect of additives such as DPPD, which are known to give a different smut thickness and morphology, it is assumed that those additives also influence the gas permeation mechanism. By using impedance data the movement of the gas inside the smut layer can be modelled.

\subsection{Pitting morphology}

$\mathrm{HCl}$ is known to give a uniform crystalographic cubic shape pitting morphology whereas $\mathrm{HNO}_{3}$ gives more shalow like pits [Terryn, 1987, Laevers, 1995] as it is illustrated in Figure 8.

It was observed by Terryn, (1987) that by increasing the frequency from 1 to $100 \mathrm{~Hz}$ we can observe a change from morphologies with locally attacked sites and discrete pits $(1 \mathrm{~Hz})$ to more uniform attacked areas with increased pitting density. A sufficient current can give uniform pitted surfaces but when a current density of $300 \mathrm{~A}_{\mathrm{rms}} \mathrm{dm}^{-2}$ is applied it can give rise to a less uniform pitting morphology [Laevers, 1995].

Thompson and Wood, (1978) showed that in $\mathrm{HCl}$, pit formation occurs at gaps in the air formed alumina film on the aluminium substrate. The gaps can be either caused mechanically due to physical features on the metal or can be associated with compositional features [Thompson \& Wood, 1978, Lindseth 1999, Afseth, 1999]. Upon graining in $\mathrm{HCl}$ a large population density of pits (more than $10^{13} \mathrm{~m}^{-2}$ ) of sizes around $160 \mathrm{~nm}$ is formed in the first cycles of electrograining and remains constant, but the smaller pits grow during the A.C. electrograining and merge with other pits leaving less plateau areas [Thompson \& Wood, 1978].

By comparing the shape of the key pits building up the surface we could conclude that the anodic metal dissolution during graining in hydrochloric acid occurs in preferred directions, while during the dissolution of aluminium in nitric acid it occurs isotropically (building up from a flat walled hemispherical pit) [Laevers 1995]. The anodic and cathodic process seems to occur on fresh surfaces at new positions for each cycle and the cube propagation starting at different points in the cubic phase appears to happen in a random way [Dyer \& Alwitt, 1981].

Pitting is preferentially following the rolling lines as observed from the first electrograining steps [Dowell, 1979, 1986]. Grain boundaries act to some extend as preferential sites for the initiation of pits [Dowell, 1979, 1986]. 

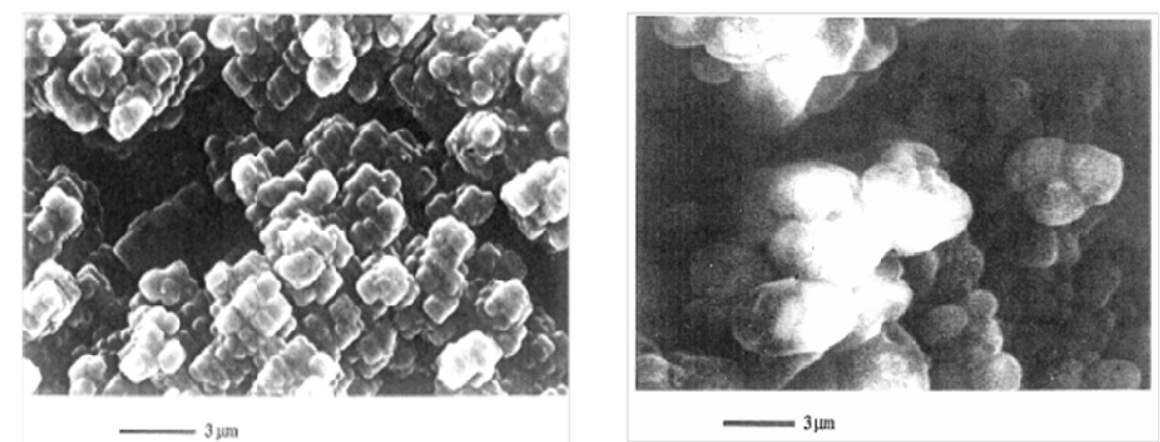

Fig. 8. Oxide replicas of pits formed during electrograining in $\mathrm{HCl}$ (left) with cubic pit building up and $\mathrm{HNO}_{3}$ (right) with flat walled hemispherical pit building up[Laevers, 1995]

The effective size of the building elements increases by increasing current density and decreasing graining frequency [Terryn et al, 1988, 1991a, 1991b]. The walls of hemispherical pits become smooth as the size of cubic pits decreases with increasing frequency [Terryn et al, 1988, 1991a, 1991b].

Intermetalics present in the substrate influence the graining mechanism. Many pits are initiated at sites of intermetalics, especially in the presensce of $\mathrm{Mg}, \mathrm{Fe}, \mathrm{Zn}$ and $\mathrm{Cu}$, but not all particles have the same active role during the electrograining [Dowell, 1986].

For $1 \mathrm{wt} \%$ of manganese alloyed aluminum plate with most of the manganese $(0.9 \mathrm{wt} \%)$ present in solid solution, a lateral and unidirectional growth of hemispherical pits occurs, creating worm-like pits [Laevers et al, 1996]. It was assumed that the worm-like pits observed are also influenced by other alloying elements present in solid solution, such as iron, silicon and titanium for AA1050 aluminum [Laevers et al, 1996].

In general it can be concluded that $\mathrm{HCl}$ and $\mathrm{HNO}_{3}$ can give different pit shapes, but in both cases during the anodic half period a large number of pits is created simultaneously and with time growth or new pits are initiated and at a certain moment some pits will merge together creating bigger pits (Figure 9). The final surface morphology can vary between uniform morphologies with homogeneously distributed pits to areas with plateaus or a non uniform distribution of pits.

\subsubsection{Pit size}

Electrograining in $\mathrm{HCl}$ gives at the first cycles large hemispherical pits in different sizes which become broader and grow till they merge [Thompson \& Wood, 1978, Terryn et al 1988, 1991a, 1991b, Dimogerontakis et al, 2006, 2007].

After electrograining in $\mathrm{HCl}$ and examining the surface at different times Lin et al (2001) reported the different evolution during the graining of the fine, hemispherical and worm like pits. Within the first 60 seconds they showed that the small dotted-like pits grow and coalescence with the fine pits to form more hemispherical pits. While the process continues the worm pits merge with the growing hemispherical pits and disappear. After around 120 
seconds most of the aluminium surface is dotted with large hemispherical pits with a uniform distribution which can lead upon further graining into the growth and merger with other hemispherical pits, forming pit sizes of $5 \mu \mathrm{m}$. In the same study cross-sectional images showed that the surface of the worm like pits is dotted with fine hemispherical pits whereas the hemispherical pits are observed with flat walls. The fine pits have a smaller depth than the hemispherical ones, which indicates that the growth of the hemispherical pits prevails and propagates into the aluminium substrate.

An increase in the current density can decrease the pit population density, but increases the mean value of the pit size [Dimogerontakis et al, 2006]. With an increased current a higher concentration of aluminium ions inside each pit is obtained during the anodic half cycle making the pore of the pit bigger while during the cathodic half cycle a larger precipitation of smut takes place due to the higher local $\mathrm{pH}$ increase [Dimogerontakis et al, 2006].
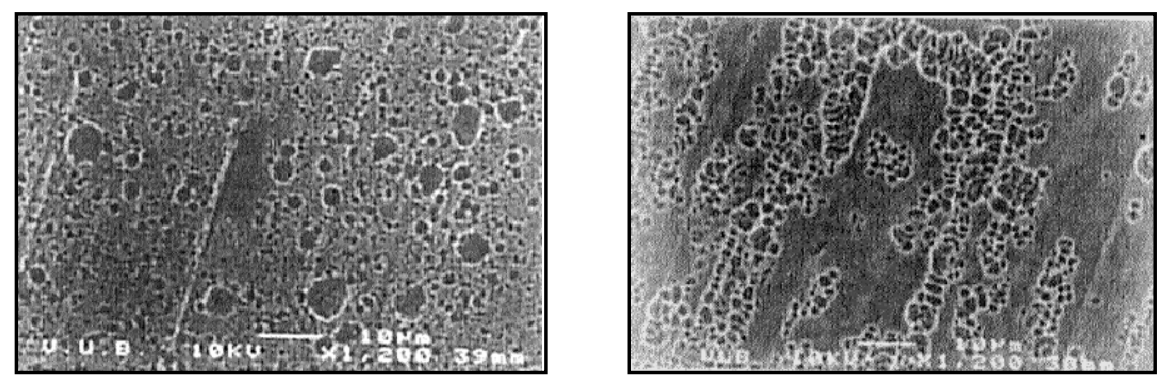

Fig. 9. Pitting morphology after electrograining with $\mathrm{HCl}$ (left) and $\mathrm{HNO}_{3}$ (right) nder the same electrograining conditions [Laevers, 1995]

\subsubsection{Correlation with smut}

A very important parameter for the development of graining morphologies is the number of sites where key pits are initiated, mainly determined by the surface condition of the aluminium substrate and the propagation rate of the sites, depending on the features of the applied alternating current [Laevers, 1995].

It was observed that the weight of the smut layer increases linearly with the consumed electric charge during graining in hydrochloric acid [Dimogerontakis et al, 2006]. By applying a high electric charge the formation of an increased smut layer will cause the repassivation of the metal resulting in the increase of the cathodic potential [Terryn 1987, Dimogerontakis et al, 2006]. A more intensive hindrance during the cathodic reaction could be due to the fact that the $\mathrm{H}_{2}$ evolution was observed to be mass transport controlled [Laevers, 1995]. In this way the formation of a thick hydrated smut layer can hinder the reaction of the hydrogen ions [Dimogerontakis et al, 2004, 2006]. An increase of the current density results in a smut layer formation with increasing size of hemispherical pits [Dimogerontakis et al, 2006]. On the other hand, a less uniform graining morphology was developed by increasing the current density [Dimogerontakis et al, 2006]. The lower the amount of formed smut the more uniform graining morphology is obtained with small hemispherical pits, a high pit population density and a more uniform size distribution. 


\section{Conclusion}

Electrograining is an important process for the lithographic printing plate industry and for aluminium capacitor foil production. The purpose of electrograining is to create a higher surface area with a convoluted surface of pits with narrow size distribution, shallow depths and no ungrained or plateaus areas.

During electrograining the aluminium surface is continuously undergoing a process of pitting and repassivation. In the anodic polarisation which occurs during the first half cycle of the electrograining period, pit formation enhanced by chloride or nitrate ions is observed while during the cathodic half cycle an increase of the $\mathrm{pH}$ due to $\mathrm{H}_{2}$ production occurs. The latter leads to the precipitation of $\mathrm{Al}(\mathrm{OH})_{3}$ on the surface creating a layer called smut. The smut is a gel that contains $5 \% \mathrm{Al}(\mathrm{OH})_{3}, 5 \% \mathrm{Al}$ and $90 \%$ water.

It is clearly seen that the understanding of the electrograining mechanism was and still remains a subject for extended research. All the different parameters analyzed give different information regarding the reactions taking place, the dissolution of aluminium, the formation of the pits, the smut deposition and the final morphology.

In this paper we presented studies mainly focusing on electrograining in $\mathrm{HCl}$ or $\mathrm{HNO}_{3}$ electrolytes. $\mathrm{HCl}$ is one of the most common used electrolytes for the electrograining of aluminium. It gives a characteristic crystallographic pitting morphology whereas a shallower pitting structure can be achieved when electrograining in HNO3 electrolyte occurs. In general both electrolytes give similar overall surface morphologies under certain electrograining conditions, but the morphology of the individual pit is still different. HF is known to give a high density of small and uniform pits. At high electrolyte concentrations and low current densities etch-like morphologies are obtained whereas with increasing current density and decreasing concentration, uniform and hemispherical pits are observed, with sizes depending on the frequency. At very low concentrations and very high current densities, a non-uniform pitting morphology is obtained because hemispherical pits grow laterally until they intersect. On the other hand with an increasing electrolyte flow across the electrodes, the surface morphology will tend towards an etch-like morphology, with no hemispherical pits.

The addition of acids can change the surface morphology. Similar morphologies to $\mathrm{HCl}$ were seen with the addition of acetic acid giving larger pits with finer features whereas the addition of citric acid results in shallower hemispherical pits. Significant difference was observed with the addition of DPPD with very deep pits and large plateau areas.

The initial substrate surface morphology can influence the final pitting morphology as it was observed in many studies. Pit initiation and nucleation were observed to occur at metallurgical, mechanical or compositional flaws in the aluminium surface. Intermetallic particles and especially $\beta$-phase particles can act as cathodic sides promoting a local coarse pit development. The presence of manganese or silicon in solid solution gives less uniform pitting morphologies whereas when iron is present shallower pits are created. Zinc and magnesium due to a fast pitting initiation give surfaces with larger pits and eliminate plateau areas.

A thin and porous etch film leads to a homogenous grained surface due to a homogenous distribution of current density. A thick and compact film containing few defects causes the 
formation of large pits and extended plateaus as a result of current concentration at the defects. With high current we can obtain less but bigger pits due to the increased amount of produced smut as a result of the high concentration of aluminium inside the pits during the anodic half period.

An important parameter for the creation of the smut layer is the presence of hydrogen at the surface of the aluminium. The amount of precipitated aluminium hydroxide will be influenced by the time needed for a sufficient amount of $\mathrm{H}^{+}$to be gathered at the surface for the $\mathrm{pH}$ to rise above 5 . The mechanism through which hydrogen gas escapes from the smut and is released in the bulk of the solution was described through SAXS data. It was proposed that when gas is trapped inside the smut a tortuous porous network is observed giving an increased pressure on the interface. This results in a more etch-like pitting morphology whereas when there is sufficient smut porosity and gas release a more uniform pitting morphology can be obtained.

A more thorough investigation regarding the smut film formation mechanism, the structure and the morphology of the smut in correlation to the hydrogen gas evolution during the cathodic polarisation on the electrograining of aluminium is necessary in order to be able to describe and correlate the influence of the hydrogen upon the final pitting morphology. Electrochemical Impedance data can give an inside observation of the retained gas; this is ongoing research yet to be published.

\section{Acknowledgment}

The authors would like to thank Josh Hammons and Yves Van Ingelgem for the support and the help they provided for the preparation of the article.

\section{References}

Afseth, A. (1999). Metallurgical control of filiform corrosion of aluminium alloys, NTNU, Ph.D. Thesis, Trondheim, Norway

Akitt, J., W. (1989). Progress in Nuclear Magnetic Resonance Spectroscopy, Volume 21, pp.1149.

Amor, M., P. \& Ball, J. (1998). The mechanism of electrograining aluminium sheet in Nitric/Boric acid electrolyte, Corrosion Science, volume 40, pp. 2155-2172

Bale, H., D. \& Schmidt, P., W. (1959). Small angle X-ray mattering from aluminium hydroxide gels, Physical Chemistry, Volume 31, pp.1612-1618.

Bottero, J., Y., Cases, J. M., Fiessinger, F. \& Poirier, J., E. (1980). Studies of hydrolysed aluminum chloride solutions, Chemical Physics, Volume 84, pp.2933-2939.

Bottero, J., Y., Tchoubar, D., Cases, J., M. \& Flessinger, F. (1982). , Investigation of the hydrolysis of aqueous solutions of aluminum chloride. 2. Nature and structure by small-angle x-ray scattering, Physical chemistry, Volume 86, pp. 3667-3673.

Bradley, S., M., Kydd, R., A., \& Howe, R., F. (1993). The structure of Al-gels formed through base hydrolysis of $\mathrm{Al}^{3+}$ aqueous solutions, Colloid Interface Science.Volume 159, pp. 405-412.

Brett, C., M., A. (1990). The application of lectrochemical impedance techniques to aluminium corrosion in acidic chloride solution, Applied Electrochemistry, Volume 20, pp. $1000-1003$ 
Bridel, F., Grynszpan, R., Bourelier, F., Bavay, J., C. \& Vu Quang, k. (1983). Passivity of metals and semiconductors, Elsevier, Amsterdam, p. 753

Buytaert, G., (2006). Study of (Sub)surface on rolled commercially pure Aluminium alloys, VUB, Ph.D. Thesis, Brussels, Belgium

Christensen, A., N., Lehmann, M., S. \& Wright, A. (1982). Acta Chemica Scandinavica Series a-Physical and Inorganic Chemistry, Volume 36, pp. 779-781.

Dimogerontakis, Th., Campestrini, P. \& Terryn, H. (2004). The influence of the current density on the AC-graining morphology, Electrochemical Society Proceedings, Volume 19

Dimogerontakis, Th., Terryn, H. \& Campestrini, P. (2006). Repassivation of aluminium during AC-graining process by aluminium hydrohide formation, $9^{\text {th }}$ International Symposium: Passivation of Metals and Semiconductors, and Properties of Thin Oxide Layers, Paris, France, June 27- July 1, 2005

Dimogerontakis, Th., \& Terryn, H. (2007). Interpretation of anodic and cathodic potential variations during AC-graining of aluminium in hydrochloric acid, Corrosion Science, Volume 49, pp. 3428-3441

Dowell, A., J. (1979). Alternating current etching of aluminium lithographic sheet, Transactions of the Institute of Metal Finishing, Volume 57), pp. 138-144

Dowell, A., J. (1986). The influence of metallurgical factures in A.C. etching of lithoplates, Transactions of the Institute of Metal Finishing, pp. 85-90.

Dyer, C., K. \& Alwitt, R., S. (1981). Surface changes during A.C. etching of aluminium, Electrochemical Society, 128, 300-305.

Hammons, J., Raymenta, T., Vandendael, I., Blajiev, O., Hubin, A., Davenport, A., J., Raes, M. \& Terryn, H. (2010). A method to detect retained gas during AC electrograining using in-situ small angle X-ray scattering, Electrochemistry Communications, Volume 12, pp. 717-719

Hammons, J. (2011). A study of precipitated films formed during electrochemically driven dissolution process, University of Birmingham, Ph.D. Thesis, Birmingham, United Kingdom,

Hebert, K. \& Alkire, R., C. (1988), Growth and passivation of aluminum etch tunnels, Electrochemical Society, Volume 135, pp. 2146-2157

Hülser, P., Krüger, U., A. \& Beck, F. (1955). The cathodic corrosion of aluminium during the electrodeposition of paint: Electrochemical measurements, Corrosion Science, Volume 38, pp. 47-57

Jackson, N., F. (1975). The tunnel etching of aluminium, Electrocomponent Science and Technology, Volume 2, pp 33-44

Johansson, G. (1960). On the Crystal Structure of Some Basic Aluminium Salts, Acta Chemica Scandinavica, Volume 14, pp. 771-773.

Kim, S., S., Lee, W., J., Pyun, S., I. \& Kim, D., R. (1999). Effects of applied potential and solution temperature on the pitting corrosion of pure aluminium in sulphate ion containing chloride solution, Metals and Materials. Volume 5, pp. 583-588.

Koroleva, E., V., Thompson, G., E., Skeldon, P., Hollrigl, G., Smith, G. \& Lockwood, S. (2005). Tailored AA1050 alloy surfaces by electrograining, Electrochimica Acta, Volume 50, pp. 2091-2106 
Laevers, P., Terryn \& H., Vereecken, J. (1992). Comparison of the A.C. electrograining of aluminium in hydrochloric and nitric acid, Transactions of the Institute of Metal Finishing, Volume 70, pp. 105-110.

Laevers, P., Terryn, H., Vereecken, J. \& Thompson, G., E. (1993). , A study of the mechanism of A.C. electrolytic graining of aluminium in hydrocloric and nitric acid, Corrosion Science, Volume 35, pp.231-238

Laevers, P. (1995). Study of the mechanism of the A.C. electrolytic graining of aluminium, VUB, Ph.D. Thesis, Brussels, Belgium

Laevers, P., Terryn, H., Vereecken, J., Kernig, B. \& Grzemba, B. (1996). The influence of Manganese on the AC electrolytic graining of aluminium, Corrosion Science, Volume 38, pp. 413-429

Laevers, P., Hubin, A., Terryn, H. \& Vereecken, J. (1998). A wall-jet electrode reactor and its application to the study of electrode reaction mechanisms Part III: Study of the mechanism of the AC electrolytic graining of aluminium in hydrochloric acid, Applied Electrochemistry, Volume 28, pp. 387-396

Lee, W., J. \& Pyun, S., I. (2000). Effects of sulphate ion additives on the pitting corrosion of pure aluminium in $0.01 \mathrm{M} \mathrm{NaCl}$ solution, Electrochimica Acta, Volume 45, pp. 1901-1910

Lin, C., S., Chang,C., C. \& Fu H.M. (2001). AC electrograining of aluminum plate in hydrochloric acid, Materials Chemistry and Physics, Volume 68, pp.217-224

Lin, C., S. \& Chiu, C., C. (2005). Formation of the Layered Etch Films on AA1050 Aluminum Plates Etched in Nitric Acid Using Alternating Currents, Electrochemical Society, Volume 152, pp. C482-C487

Lin, C., S. \& Li, W., J. (2006). Pitting Behavior of Aluminum Foil during Alternating Current Etching in Hydrochloric Acid Containing Sulfate Ions, Electrochemical Society, Volume 153, pp. C51-C56

Lindseth, I. (1999). Optical total reflectance, near-surface microstructure and topography of rolled aluminium materials, NTNU, Ph.D. Thesis, Trondheim, Norway

Marshall, G., J. \& Ward, J., A. (1995). Material Science Technology, Volume 11, pp. 1015

Martinez-Caicedo, C., E., Koroleva, E., V., Thompson, G., E., Skeldon, P., Shimizu, K., Habazaki, H. \& Hoellrigl, G. (2002). Surface nanotextures on aluminium, Surface and Interface Analysis, Volume 34, pp. 405-408

Meng, G., Wei, L., Zhang, T., Shao, Y., Wang, F., Dong, C. \& Li, X. (2009). Effect of microcrystallization on pitting corrosion of pure aluminium, Corrosion Science, Volume 51, pp. 2151-2157

Ono, S. \& Habazaki, H. (2009). Effect of sulfuric acid on pit propagation behavior of aluminium under AC etch process, Corrosion Science, Volume 51, pp.2364-2370

Ono, S. \& Habazaki, H. (2010). Role of cathodic half-cycle on AC etch process of aluminium, Corrosion Science, Volume 52, pp. 2164-2171

Ono, S. \& Habazaki, H. (2011). Pit Growth Behavior of Aluminium under Galvanostatic Control, Corrosion Science, Accepted Manuscript: 22 June 2011

Pourbaix, M. (1974). Atlas of electrochemical equilibria in aqueous solutions, National Association of Corrosion Engineers, Houston, USA

Raes, M. (2009) Internal Report, Vrije Universiteit Brussels, Belgium 
Rodriguez, B., Kernig, B., Hasenclever, J. \& Terryn, H. (2011) Influence of the surface activation and local pitting susceptibility on the AC-electrograining of aluminium alloys, Corrosion Science, Volume 53, pp. 930-938

Sanchez, S., A., Gonzalez-Garcia, J., Esclapez, M., D., Diez-Garcia, M., I., Del Rio, J., F. \& Gazapo, J., L. (2010). Electrograining of aluminium in $\mathrm{HCl}$ : effect of the alloy for high-speed processing lines, Surface and Interface Analysis, Volume 42, pp. 311-315

Schaefer, D., W., Shelleman, R., A., Keefer, K., D. \& Martin, J., E. (1986). Equilibrium structure and rigidity of alumina polymers, Physica A:Statistical Mechanics and its Applications, Volume 140, pp. 105-113

Smialowska, S., Z. (1986). Pitting Corrosion of Metals, National Association of Corrosion Engineers, Houston, Texas

Smialowska, S., Z. (1999). Pitting Corrosion of Aluminium, Corrosion Science, Volume 41, pp. 1743-1767

Sinko, K., Mezei, R., Rohonczy, J. \& Fratzl, P. (1999). Gel Structures Containing Al(III), Langmuir: surfaces and colloids, Volume 15, pp. 6631-6636.

Thompson, G., E., \& Wood, G., C. (1978). The effect of alternating voltage on aluminium electrodes in hydrochloric acid, Corrosion Science, Volume 18, pp. 721-746

Terryn, H. (1987). Electrochemical Investigation of AC Electrograining of Aluminium and its porous anodic oxidation, Ph.D. Thesis, Brussels, Belgium

Terryn, H., Vereecken, J. \& Thompson, G., E. (1988), Electrograining of aluminum, Transactions of the Institute of Metal Finishing, Volume 66, pp. 116-121

Terryn, H., Vereecken, J. \& Thompson, G., E. (1991a), The electrograining of aluminium in Hydrochloric acid- I. Morphological appearance, Corrosion Science, Volume 32, pp. 1159-1172

Terryn, H., Vereecken, J. \& Thompson, G., E. (1991b), The electrograining of aluminium in Hydrochloric acid- II. Morphological appearance, Corrosion Science, Volume 32, pp 1173-1188

Tomasoni, F., Van Parys, H., Terryn, H., Hubin, A. \& Deconinck, J. (2010). Identification of bubble evolution mechanisms during AC electrograining, Electrochemistry Comminications, Volume 12, pp. 156-159

Tomcsanyi, L., Varga, K., Bartik, I., Horanyi, G. \& Maleczki, E. (1989). Electrochemical study of the pitting corrosion of aluminium and its alloys. II. Study of the interaction of chloride ions with a passive film on aluminium and initiation of pitting corrosion, Electrochimica Acta, Volume 34, pp.855-859.

Vargel, C., Jacques, M. \& Schmidt, M., P. (2004). Corrosion of Aluminium, Elsevier, pp. 81605

Wilson, B., P., Dotremont, A., Biesemans, M., Willem, R., Campestrini, P. \& Terryn, H. (2008). Effect of Additives on Smut-layer Formation and Pitting during Aluminium Etching in Hydrochloric Acid, Electrochemical Society, Volume 155, pp. C22-C31

Wilson, B. (2006), Internal Report, Vrije Universiteit Brussels, Belgium 


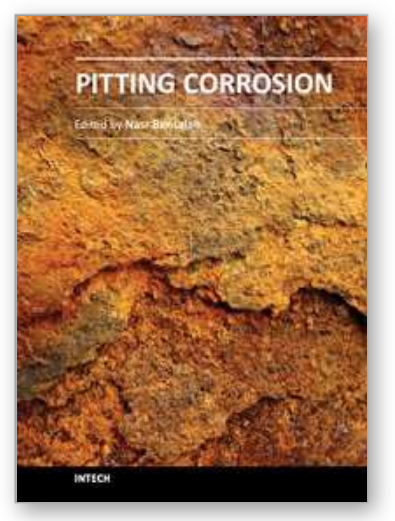

\author{
Pitting Corrosion \\ Edited by Prof. Nasr Bensalah
}

ISBN 978-953-51-0275-5

Hard cover, 178 pages

Publisher InTech

Published online 23, March, 2012

Published in print edition March, 2012

Taking into account that corrosion is costly and dangerous phenomenon, it becomes obvious that people engaged in the design and the maintenance of structures and equipment, should have a basic understanding of localized corrosion processes. The Editor hopes that this book will be helpful for researchers in conducting investigations in the field of localized corrosion, as well as for engineers encountering pitting and crevice corrosion, by providing some basic information concerning the causes, prevention, and control of pitting corrosion.

\title{
How to reference
}

In order to correctly reference this scholarly work, feel free to copy and paste the following:

Maria Tzedaki, Iris De Graeve, Bernhard Kernig, Jochen Hasenclever and Herman Terryn (2012). Importance of Etch Film Formation During AC Controlled Pitting of Aluminium, Pitting Corrosion, Prof. Nasr Bensalah (Ed.), ISBN: 978-953-51-0275-5, InTech, Available from: http://www.intechopen.com/books/pittingcorrosion/importance-of-etch-film-formation-during-ac-controlled-pitting-of-aluminium

\section{INTECH}

open science | open minds

\section{InTech Europe}

University Campus STeP Ri

Slavka Krautzeka 83/A

51000 Rijeka, Croatia

Phone: +385 (51) 770447

Fax: +385 (51) 686166

www.intechopen.com

\section{InTech China}

Unit 405, Office Block, Hotel Equatorial Shanghai

No.65, Yan An Road (West), Shanghai, 200040, China

中国上海市延安西路65号上海国际贵都大饭店办公楼405单元

Phone: $+86-21-62489820$

Fax: +86-21-62489821 
(C) 2012 The Author(s). Licensee IntechOpen. This is an open access article distributed under the terms of the Creative Commons Attribution 3.0 License, which permits unrestricted use, distribution, and reproduction in any medium, provided the original work is properly cited. 